\title{
Spirometric Evaluation of Airflow Limitation In Diabetics
}

\section{Authors \\ Nookala Sunil Kumar D.T.C.D, DNB, Gali Prakash Vignan Kumar M.D, Bhavana Grandhi M.D, Tajik Mohammed Shafi (PG), Jyothi P D.T.C.D}

Department of Pulmonology, Narayana Medical College and Hospital, Chinthareddypalem, Nellore, Andhra Pradesh, India

Email:sunil98kmc@yahoo.co.in,galiprakashvignan@gmail.com,drbhavana.grandhi@gmail.com, drtajikmohammed@gmail.com,chintakumar1974@gmail.com

Corresponding Author

Dr Nookala Sunil Kumar

1/1278, Nawabpeta, Bunglathota, Nellore, Andhra Pradesh, India.

Email: sunil98kmc@yahoo.co.in, Mobileno.9885652733

\begin{abstract}
Background: Diabetes is a growing public health problem especially in India. The lung may be a target organ in diabetic subjects because of the presence of microvascular circulation and connective tissue. Non enzymatic glycosylation of connective tissue in chronic hyperglycemia leads to end organ damage and lung functions were reduced in diabetic subjects as compared to the normal subjects.

Aim: To assess the pulmonary function tests in diabetic subjects.

Materials and methods: An observational study was done over a period of one year in diabetic subjects. Pulmonary function tests were done and the glycemic status of all these subjects was assessed.

Results: Study population included 137subjects with female to male ratio of 1.17:1.0. Among men, 33 were smokers and remaining 30 were non smokers. The predominant pattern in all subjects was restrictive type. Siginificant $p$ value was seen when the duration of diabetes was compared with FEVI/FVC.

Conclusion: Thus our study emphasizes the alteration of the lung functions with the duration of diabetes.

Keywords: Diabetes, Lung function tests.
\end{abstract}

\section{Introduction}

Diabetes is a systemic disease ${ }^{1}$ and its prevalence in adults worldwide was estimated to be $4 \%$ in 1995 and is estimated to rise to $5.4 \%$ in $2025^{2}$. The presence of an extensive pulmonary microvascular circulation and abundant connective tissue raises the possibility that lung may be a target organ of the pathologic process induced by chronic hyperglycemia ${ }^{1}$. The interest in the relationship between diabetes and obstructive lung diseases has been pursued only recently ${ }^{4-7}$. Chronic obstructive pulmonary disease (COPD) may be a risk factor for developing type 2 diabetes ${ }^{5}$. 
Hyperglycemia is associated with adverse clinical outcomes in patients with acute exacerbations of $\mathrm{COPD}^{6}$. A better understanding of the relationship of COPD to novel risk factors, such as hyperglycemia and diabetes is necessary for the exploitation of the potential for interventions that improve mortality and even reverse the course of the disease in $\mathrm{COPD}^{7}$ and also bring out newer and novel therapeutic approaches in this subgroup of patients. ${ }^{8}$

With this background, this study was undertaken to determine the pulmonary function parameters in patients of diabetes mellitus (NIDDM).

\section{Materials \& Methods}

A descriptive observational study was done over a period of one year at mediciti hospitals hyderabad and narayana general hospitals. patients with type 2 diabetes mellitus who attended Imedical, pulmonology ,endocrinology op were included in the study after obtaininig their consent and after obtaining the permission of ethical committe The lung function of these patients were evaluated using Spirometry and assessed it with duration of diabetes, glycemic control in smokers versus nonsmokers.

\section{Inclusion criteria}

1. Patients of type 2 diabetes mellitus of at least 6 months duration

2. Patients without past history of any lower respiratory illness

3. Smokers of $>10$ pack years

\section{Exclusion criteria}

1. Patients with current or recent upper respiratory tract infections or lower respiratory tract infection

2. Patients with history of occupational exposure to any substance that would affect lung function

3. Individuals with unacceptable spirometric technique due to cough, obstruction of teeth or tongue.

4. Recent surgery
Spirometry was performed in sitting position. FVC (forced vital capacity) and FEV1 (forced expiratory volume in 1 second) was measured using standard guidelines. The best of three acceptable curves were selected. The ratio of FEV1 to FVC was also calculated. FEV1 is decreased in obstructive lung disease; FVC is normal or slightly decreased. FVC is significantly decreased in restrictive lung disorders along with FEV1.

HbA1c is a minor component of hemoglobin to which glucose is bound. HbA1c is referred to as Glycosylated hemoglobin or glycol hemoglobin.HbA1c levels are not influenced by daily fluctuations in the blood glucose concentration but reflect the average glucose levels over the prior 6-8 weeks. It is a useful indicator of how well the blood glucose level has been controlled in the recent past and may be used to monitor the effects of diet, exercise and drug therapy on blood glucose in people with diabetes. The study population was divided into 3 groups as male smoker, male non smoker, female groups. Stastical analysis was done. Mean, Standard deviations are calculated for age, height, weight, BMI, FEV1, FVC, FEV1/FVC, FEV 1\%. For intra group variable analysis, SD was calculated \& mean differences were compared by T-tests / ANOVA

Values with probability $<0.05$ was considered to be statistically significant.

\section{Results}

Over a period of one year Spirometry was performed on 137 diabetic patients

\section{Sex distribution}

74 were female patients and 63 were male patients with the female to male ratio of 1.17:1.0. Graph 1. Among the male patients 30 were smokers and 33 were non smokers

\section{Age distribution}

The mean age of male smokers in the study was 56.46 years, the mean age of male non smokers was 57.78 years and that of female subjects was 51.89 years. Table I, Graph 2 . 


\section{Body Mass Index}

The BMI of male smokers was 24.58 , male non smokers was 23.96 and that of females was 27.53. Table II, Graph 3.

\section{Duration of diabetes mellitus}

The mean duration of DM in subjects participated in this study was for males it was 61.03 months and for female subjects it was 73.04 months. Table III, Graph4

\section{HbA1c}

It was done in 53 out 63 male subjects and 59 out of 74 female subjects. In males, mean HbA1c was 8.29 and females it was 8.36. The overall glycemic control was poor in all subjects.

\section{FBS and PPBS}

FBS in male subjects ranged from $65-470$ and in females ranged from70 -408.PPBS in male subjects ranged from 145-525 and female subjects from 140- 496.Table IV,Graph5

\section{Spirometry}

Spirometry was performed in all subjects. Duration of DM was compared with spirometric abnormality. Restrictive abnormality was seen in diabetics of 5 years duration where as obstructive type was seen when duration was less than 4 years.

In male smokers (30), the patterns were as follows i.e. restrictive in 3 subjects (10\%), obstructive in 12 subjects $(40 \%)$, mixed in 11 subjects $(36.67 \%)$ and normal in the remainder (13.33\%). Table V

In male non smokers (33) the restrictive pattern was predominant $(57.57 \%)$ followed by normal pattern and 1 each with obstructive and mixed pattern respectively. Table VI.

In female subjects (74) who were completely non smokers, restrictive pattern is the predominant pattern seen in $41(56.16 \%)$ subjects, obstructive in $7(9.45 \%)$, mixed in $2(2.7 \%)$, and normal in 24 subjects $(32.87 \%)$. Table VII

The overall spirometry pattern in all subjects is illustated in Graph 6

When correlation was done between duration of DM with FEV1, FVC and FEV1/FVC of smoker male subjects, we found a negative correlation of 0.17, 0.22 with FEV1 and FVC (Graph7) respectively whereas a positive correlation of 0.13 is found between duration and FEV1/FVC, Graph 8 .

When correlation was done between duration of DM with FVC,(Graph9) FEV1,(Graph 10) and FEV1/FVC of non smoker male subjects we found a negative correlation of $0.23,0.18$, and 0.04 respectively.

When correlation was done between duration of DM with FEV1, FVC and FEV1/FVC of nonsmoker female subjects, we found a negative correlation of 0.19and 0.21with FEV1 (Graph11) and FVC (Graph12) respectively whereas a positive correlation of 0.05 is found between duration of DM and FEV1/FVC (Graph13)

Spirometric results in males and females (mean values).

In both males and females, $\mathrm{p}$ value was significant for FVC, FEV1.Table 8, Table 9.

\section{Body Mass Index Vs Spirometric abnormality.}

In male smokers, the predominant pattern in over weight subjects was obstructive whereas it was mixed in moderately obese patients. Table $X$

In male non smokers, the predominant pattern in over weight subjects was restrictive. Table XI.

In females, the predominant pattern in over weight and obese subjects was restrictive. Table XII

FBS Vs Spirometric abnormality

FBS was recorded in all subjects. In male smokers , majority of them (29.97\%) had an obstructive pattern whose FBS >126. whereas in male non smokers, the predominant pattern was restrictive with $(51.5 \%)$ FBS > 126. TableXIII, Table XIV. In female subjects, restrictive pattern was seen in patients whose FBS $>126$ i.e.47.25\%.Table XV PPBS Vs Spirometric abnormality. PPBS in most of the subjects was $>200 \mathrm{mg} / \mathrm{dl}$ .Male smokers had mixed pattern (29.97\%), whereas male non smokers $(51.5 \%)$ and females (45.9\%) had restrictive pattern. Table XVI,XVII,XVIII. 
Table I Age distribution

\begin{tabular}{|c|c|c|c|c|c|c|}
\hline Gender & Smoking history & No & Min & Max & Mean & SD* \\
\hline \multirow[b]{2}{*}{ Male } & Smoker & 30 & 42 & 73 & 56.46 & 8.86 \\
\hline & Non smoker & 33 & 27 & 79 & 57.78 & 10.61 \\
\hline Female & --- & 74 & 32 & 85 & 51.89 & 10.44 \\
\hline
\end{tabular}

- Standard deviation

Table III Duration of diabetes mellitus

\begin{tabular}{|l|l|l|l|l|l|}
\hline Gender & No. & Min. & Max. & Mean & SD* \\
\hline Male & 63 & 6 & 144 & 61.03 & 33.66 \\
\hline Female & 74 & 6 & 240 & 73.04 & 53.76 \\
\hline
\end{tabular}

*Standard deviation

Table IV. FBS and PPBS values in males and females

\begin{tabular}{|l|l|l|l|l|l|l|}
\hline & & No & Min. & Max. & Mean & SD* \\
\hline \multirow{3}{*}{ Male } & FBS $\dagger$ & 63 & 65 & 470 & 173.52 & 77.78 \\
\cline { 2 - 7 } & PPBS $\$$ & 63 & 145 & 525 & 257.17 & 83.93 \\
\hline & FBS & 74 & 70 & 408 & 178.72 & 64.63 \\
\hline Female & PPBS & 74 & 140 & 496 & 268.32 & 77.49 \\
\hline
\end{tabular}

$\dagger$ Fasting blood sugar

\$Post prandial blood sugar

Table V. Spirometry pattern in male smokers.

\begin{tabular}{|l|l|l|l|l|} 
Duration of diabetes & Restrictive & Obstructive & Mixed & Normal \\
\hline $\begin{array}{c}6-12 \text { months } \\
13-24 \text { months }\end{array}$ & $1(3.33 \%)$ & $3(9.99 \%)$ & & $1(3.33 \%)$ \\
\hline $25-36$ months & & & & \\
\hline $37-48$ months & & $5(16.65 \%)$ & $3(9.99 \%)$ & $3(9.99 \%)$ \\
$49-60$ months & $1(3.33 \%)$ & $3(9.99 \%)$ & $3(9.99 \%)$ & \\
\hline $61-72$ months & $1(3.33 \%)$ & & $4(13.33 \%)$ & \\
\hline $73-85$ months & & & & \\
\hline $85-96$ months & & & & \\
\hline $97-108$ months & & $1(3.33 \%)$ & & \\
\hline $109-120$ months & & & $1(3.33 \%)$ & \\
\hline$>120$ months & & & & \\
\hline
\end{tabular}

Table VI. Spirometry pattern in male non smokers

\begin{tabular}{|l|l|l|l|l|}
\hline Duration of diabetes & Restrictive & Obstructive & Mixed & Normal \\
\hline 6-12 months & $1(3.03 \%)$ & & & \\
\hline $13-24$ months & & & & $3(9.09 \%)$ \\
\hline $25-36$ m months & $1(3.03 \%)$ & $1(3.03 \%)$ & & $7(21.21 \%)$ \\
\hline $37-48$ months & & & & $1(3.03 \%)$ \\
\hline $49-60$ months & $2(6.06 \%)$ & & & $1(3.03 \%)$ \\
\hline $61-72$ months & $2(6.06 \%)$ & & & \\
\hline $73-84$ months & $1(3.03 \%)$ & & & \\
\hline $85-96$ months & $4(12.12 \%)$ & & & \\
\hline $97-108$ months & $1(3.03 \%)$ & & & \\
\hline $109-120$ months & $5(15.15 \%)$ & & $1(3.03 \%)$ & \\
\hline$>120$ months & $2(6.06 \%)$ & & & \\
\hline
\end{tabular}


Table VII. Spirometry pattern in females

\begin{tabular}{|l|l|l|l|l|}
\hline Duration of diabetes & Restrictive & Obstructive & Mixed & Normal \\
\hline $6-12 \mathrm{M}$ & $4(5.4 \%)$ & & & $6(8.1 \%)$ \\
\hline $13-24 \mathrm{M}$ & $2(2.70 \%)$ & $1(1.35 \%)$ & & $1(1.35 \%)$ \\
\hline $25-36$ & & $1(1.35 \%)$ & & $1(1.35 \%)$ \\
$37-48$ & $8(10.8 \%)$ & $1(1.35 \%)$ & & $4(5.4 \%)$ \\
\hline $49-60$ & $6(8.1 \%)$ & & $1(1.35 \%)$ & $3(4.05 \%)$ \\
\hline $61-72$ & $7(9.45 \%)$ & $2(2.70 \%)$ & & $2(2.70 \%)$ \\
\hline $73-84$ & $4(5.4 \%)$ & & $1(1.35 \%)$ & $1(1.35 \%)$ \\
\hline $85-96$ & $4(5.4 \%)$ & $1(1.35 \%)$ & & \\
\hline $97-108$ & & & & \\
\hline $109-120$ & & & & \\
\hline$>120$ & $6(8.1 \%)$ & $1(1.35 \%)$ & & $6(8.1 \%)$ \\
\hline
\end{tabular}

Table VIII. Spirometric results in males and females.(Mean values)

\begin{tabular}{|l|l|l|l|}
\hline & Male MEAN(SD*) & Female MEAN(SD*) & P value \\
\hline FVC & $2.64(.73)$ & $1.80(.56)$ & 0.0005 \\
FEV1 & $2.03(.62)$ & $1.51(.50)$ & 0.0003 \\
\hline FEV1/FVC & $74.78(11.56)$ & $84.55(12.36)$ & 0.21 \\
\hline \% of predicted FVC & $67.70(24.03)$ & $78.54(19.52)$ & 0.004 \\
\hline \% of predicted FEV1 & $80.41(24.72)$ & $86.26(29.78)$ & 0.218 \\
\hline FEV1/FVC \% & $96.16(14.53)$ & $108.67(20.39)$ & 0.00008 \\
\hline
\end{tabular}

*Standard deviation

Table 9. Spirometric results in males (smokers and non smokers). Mean values

\begin{tabular}{|l|l|l|l|}
\hline & $\begin{array}{l}\text { MALE Smoker } \\
\text { MEAN(SD*) }\end{array}$ & $\begin{array}{l}\text { MALE Non } \\
\text { smoker(SD*) }\end{array}$ & P VALUE \\
\hline FVC & $2.40(.70)$ & $2.86(.69)$ & 0.006 \\
FEV1 & $1.77(.55)$ & $2.27(.59)$ & 0.005 \\
\hline FEV1/FVC & $73.90(12.45)$ & $79.32(10.20)$ & 0.003 \\
\hline$\%$ of predicted FVC & $62.95(20.78)$ & $72.02(26.21)$ & 0.06 \\
\hline \% of predicted FEV1 & $68.13(18.23)$ & $91.58(24.75)$ & 0.00006 \\
\hline FEV1/FVC \% & $91.66(14.97)$ & $100.25(13.03)$ & 0.01 \\
\hline
\end{tabular}

*Standard deviation 
Table X. Spirometric abnormality with relation to BMI in male smokers

\begin{tabular}{|l|l|l|l|l|}
\hline Body Mass Index & Restrictive & Obstructive & Mixed & Normal \\
\hline$>18.5$ (underweight) & & & $2(6.66 \%)$ & \\
\hline 18.5-24.9(healthy) & $3(9.99 \%)$ & $5(16.65 \%)$ & $3(9.99 \%)$ & $1(3.33 \%)$ \\
$25-29.9$ (over weight) & & $7(23.31 \%)$ & $5(16.65 \%)$ & $3(9.99 \%)$ \\
\hline $30-34.9$ (obese) & & & & \\
\hline $35-39.9$ (moderate obese) & & & $1(3.33 \%)$ & \\
\hline$>40($ extreme obese) & & & & \\
\hline
\end{tabular}

Table XI. Spirometric abnormality with relation to BMI in male non smokers

\begin{tabular}{|l|l|l|l|l|}
\hline BMI & R & O & M & N \\
\hline$>18.5$ (underweight) & & & & $1(3.03 \%)$ \\
\hline $18.5-24.9$ (healthy) & $13(39.39 \%)$ & $1(3.03 \%)$ & & $6(18.18 \%)$ \\
\hline $25-29.9$ (over weight) & $6(18.18 \%)$ & & $1(3.03 \%)$ & $4(12.12 \%)$ \\
\hline $\begin{array}{l}30-34.9 \text { (obese) } \\
35-39.9 \text { (mod. obese) }\end{array}$ & & & & $1(3.03 \%)$ \\
\hline$>40$ (extreme obese) & & & & \\
\hline
\end{tabular}

Table XII. Spirometric abnormality with relation to BMI in females

\begin{tabular}{|l|l|l|l|l|}
\hline BMI & R & O & M & N \\
\hline$>18.5$ (underweight) & $2(2.70 \%)$ & & & \\
\hline $18.5-24.9$ (healthy) & $13(17.55 \%)$ & $3(4.05 \%)$ & $1(1.35 \%)$ & $7(9.45 \%)$ \\
\hline $25-29.9$ (over weight) & $15(20.25 \%)$ & $1(1.35 \%)$ & & $12(16.2 \%)$ \\
\hline $30-34.9$ (obese) & $7(9.45 \%)$ & $2(2.70 \%)$ & & $3(4.05 \%)$ \\
\hline $35-39.9$ (mod. obese) & $3(4.05 \%)$ & $2(2.70 \%)$ & & \\
\hline$>40($ extreme obese) & $1(1.35 \%)$ & & & $2(2.70 \%)$ \\
\hline
\end{tabular}


Table XIII: Spirometric abnormality in relation to FBS in male smokers.

\begin{tabular}{|l|l|l|l|l|}
\hline FBS & Restrictive & Obstructive & Mixed & Normal \\
\hline$<110($ NGT $)$ & & $2(6.66 \%)$ & $1(3.33 \%)$ & $3(9.99 \%)$ \\
\hline $110-125($ IGT $)$ & & $1(3.33 \%)$ & $2(6.66 \%)$ & \\
\hline$>126$ & $3(9.99 \%)$ & $9(29.97 \%)$ & $8(26.64 \%)$ & $1(3.33 \%)$ \\
\hline
\end{tabular}

TableXIV. Spirometric abnormality in relation to FBS in male non smokers.

\begin{tabular}{|l|l|l|l|l|}
\hline FBS & Restrictive & Obstructive & Mixed & Normal \\
\hline$<110($ NGT) & $1(3.03 \%)$ & & & $5(15.15 \%)$ \\
\hline $110-125(\mathrm{IGT})$ & $1(3.03 \%)$ & $1(3.03 \%)$ & & $2(6.06 \%)$ \\
$>126$ & $17(51.51 \%)$ & & $1(3.03 \%)$ & $5(15.15 \%)$ \\
\hline
\end{tabular}

Table XV:Spirometric abnormality in relation to FBS in females.

\begin{tabular}{|l|l|l|l|l|}
\hline FBS & Restrictive & Obstructive & Mixed & Normal \\
\hline$<110($ NGT $)$ & $4(5.4 \%)$ & $2(2.70 \%)$ & $1(1.35 \%)$ & $2(2.70 \%)$ \\
$110-125(\mathrm{IGT})$ & $2(2.70 \%)$ & & $3(4.05 \%)$ \\
\hline$>126$ & $35(47.25 \%)$ & $4(5.4 \%)$ & $2(2.70 \%)$ & $19(25.65 \%)$ \\
\hline
\end{tabular}

TableXVI. Spirometric abnormality in relation to PPBS in male smokers.

\begin{tabular}{|l|l|l|l|l|}
$\begin{array}{l}\text { PPBS } \\
<140\left(\mathrm{NGT}^{*}\right)\end{array}$ & Restrictive & Obstructive & Mixed & Normal \\
$140-199\left(\mathrm{IGT}^{\dagger}\right)$ & & $4(13.32 \%)$ & $2(6.66 \%)$ & $2(6.66 \%)$ \\
\hline$>200$ & $3(9.99 \%)$ & $8(26.64 \%)$ & $9(29.97 \%)$ & $2(6.66 \%)$ \\
\hline
\end{tabular}

*Normal glucose tolerance

$\dagger$ Impaired glucose tolerance

TableXVII. Spirometric abnormality in relation to PPBS in male non smokers.

\begin{tabular}{|l|l|l|l|l|} 
PPBS & Restrictive & Obstructive & Mixed & Normal \\
\hline $\begin{array}{l}<140\left(\text { NGT }^{*}\right) \\
140-199\left(\text { IGT }^{\dagger}\right)\end{array}$ & $2(6.06 \%)$ & & & \\
\hline$>200$ & $17(51.51 \%)$ & $1(3.03 \%)$ & & $6(18.18 \%)$ \\
\hline
\end{tabular}

*Normal glucose tolerance

$\dagger$ Impaired glucose tolerance 
TableXVIII. Spirometric abnormality in relation to PPBS in females.

\begin{tabular}{|l|l|l|l|l|}
\hline $\begin{array}{l}\text { PPBS } \\
<140\left(\mathrm{NGT}^{*}\right)\end{array}$ & Restrictive & Obstructive & Mixed & Normal \\
\hline $140-199\left(\mathrm{IGT}^{\dagger}\right)$ & $7(9.45 \%)$ & $1(1.35 \%)$ & & $6(8.1 \%)$ \\
\hline$>200$ & $34(45.9 \%)$ & $6(8.1 \%)$ & $2(2.70 \%)$ & $18(24.3 \%)$ \\
\hline
\end{tabular}

*Normal glucose tolerance

$\dagger$ Impaired glucose tolerance

Table XIX. Study design

\begin{tabular}{|l|l|l|l|l|}
\hline Name of study & Total no of patients & Mean age & $\begin{array}{l}\text { Mean duration of } \\
\text { diabetes }\end{array}$ & $\begin{array}{l}\text { Inclusion of } \\
\text { smokers }\end{array}$ \\
\hline Hiroshi mori et $\mathrm{al}^{9}$ & 80 & $57.9 \mathrm{yrs}$ & $10.8 \mathrm{yrs}$ & Yes \\
\hline Present study & 137 & $55.4 \mathrm{yrs}$ & $5.6 \mathrm{yrs}$ & Yes \\
\hline
\end{tabular}

Graph 1. Sex distribution

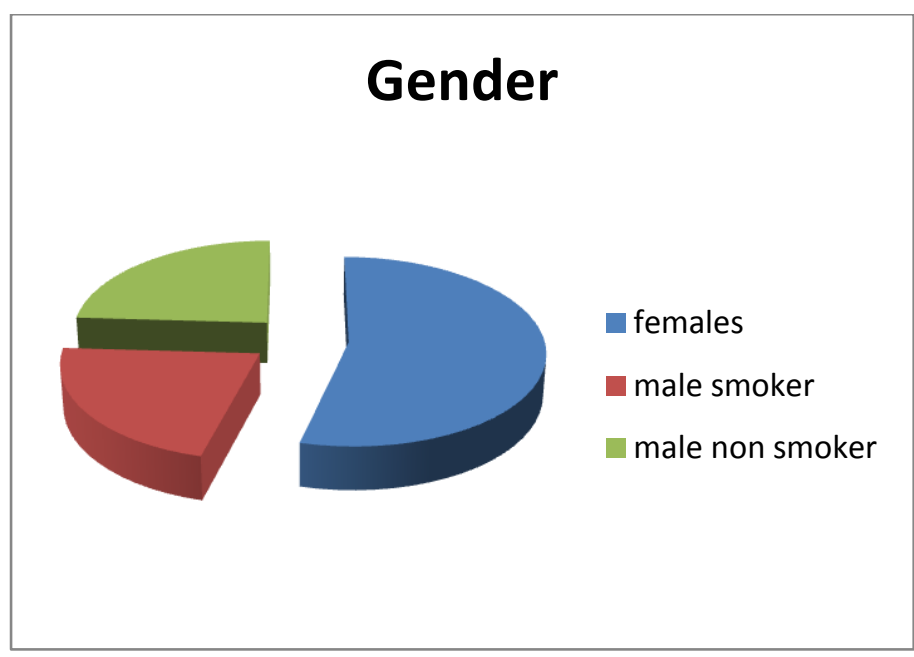

Numerical data - Graph 1

Total number of subjects -137

Females -74

Males - 63: Smokers - 30, Non smokers - 33

Graph 2.Age distribution

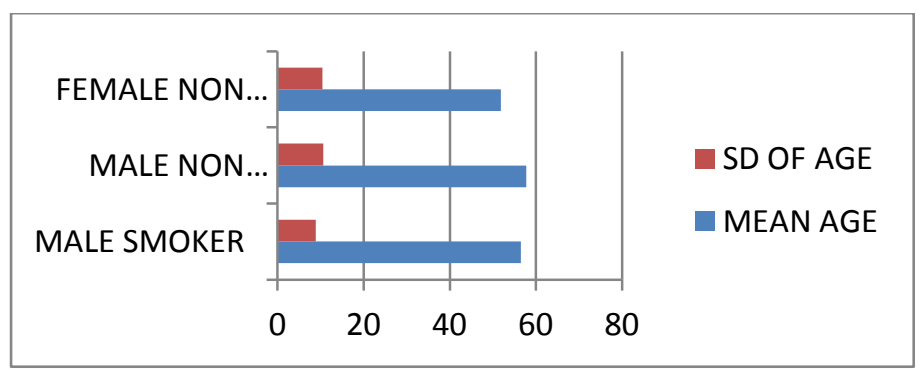

Numerical data - Graph 2

Mean age:

Males : Smokers - 56.46, Non smokers - 57.78

Females -51.89 
Graph 3.Body Mass Index

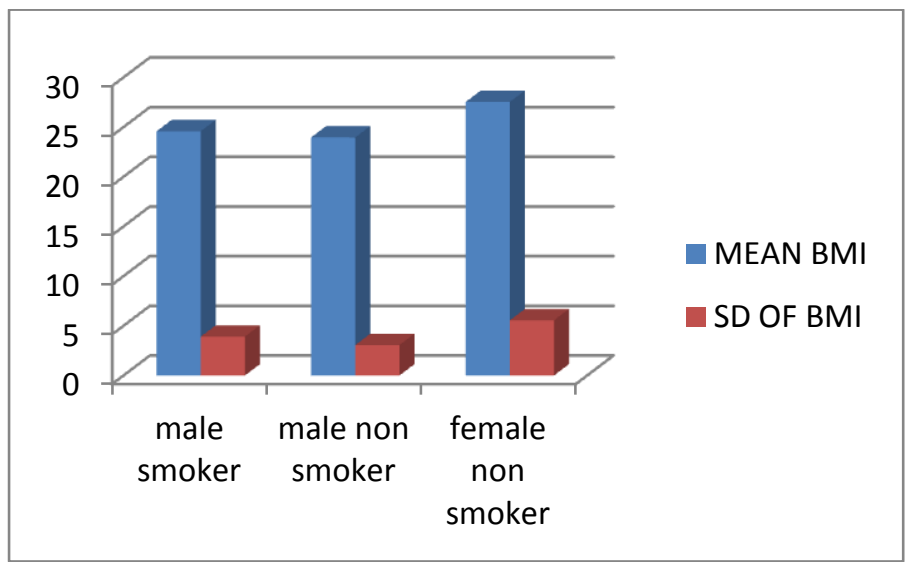

Numerical data - Graph 3

BMI:

Males:Smokers - 24.58, Non smokers - 23.96

Females- 27.53.

Graph 4.Duration of Diabetes Mellitus

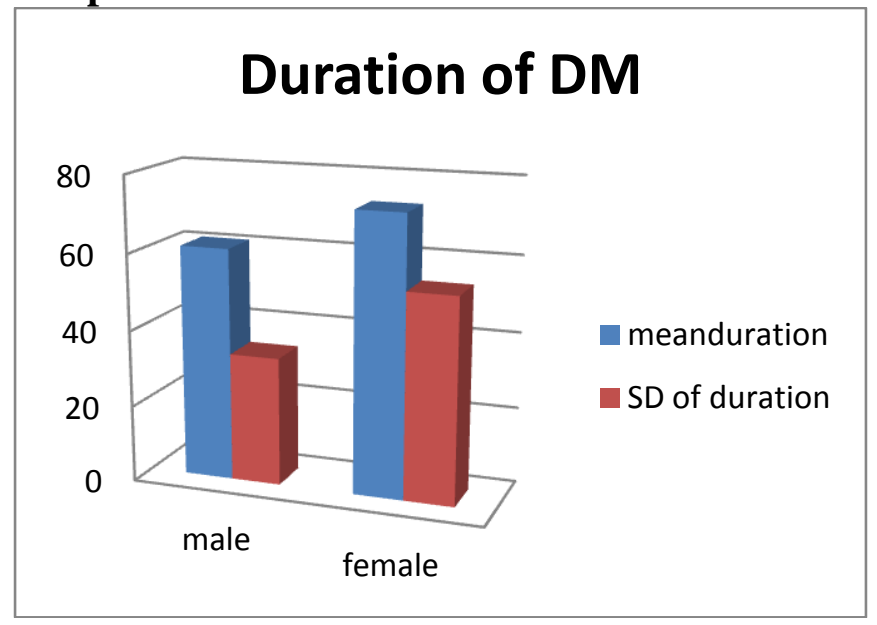

Numerical data - Graph 4

Mean Duration of Diabetes Mellitus

Males - 61.03 months, Females- 73.04 months.

Standard deviation of Duration of Diabetes Mellitus

Males - 33.66months, Females- 53.76 months.

Graph 5. FBS and PPBS in males and females

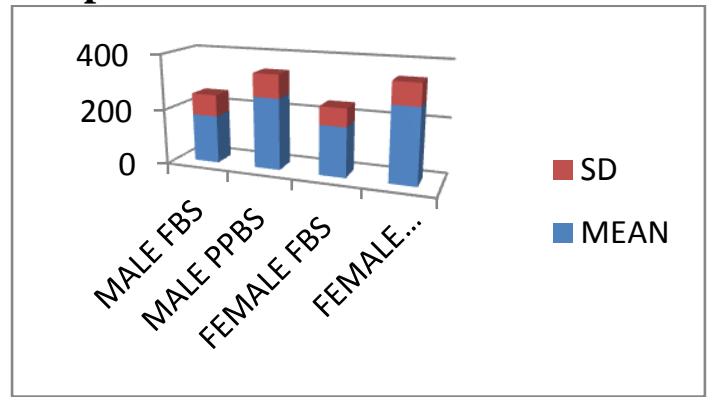

Numerical data - Graph 5

FBS: Males - 65-470,Females -70 -408.

PPBS: Males-145-525,Female-140- 496. 
Graph 6. Spirometry pattern

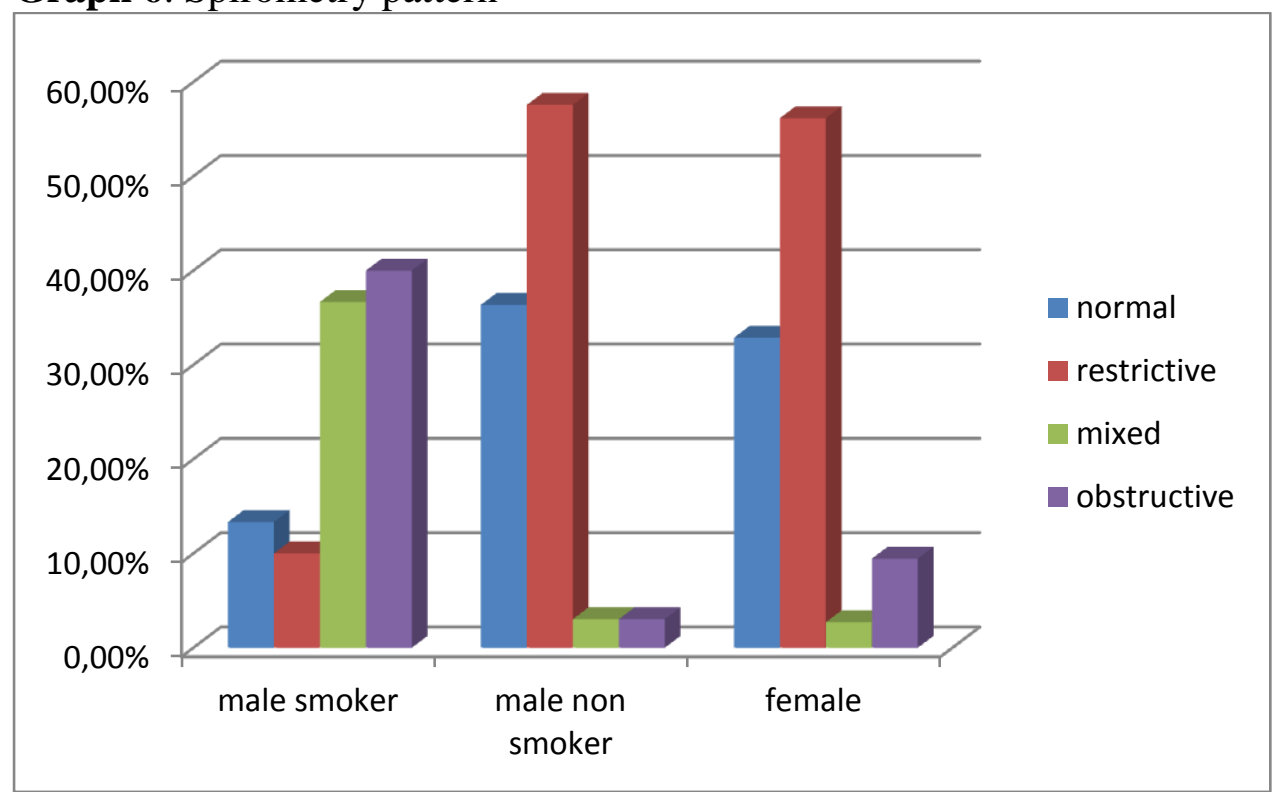

Numerical data - Graph 6

Male smokers (30):Obstructive -12 (40\%)

Restrictive - $3(10 \%)$

Mixed -11 (36.67\%)

Normal - 4(13.33\%).

Male Non smokers (33):Restrictive - 19(57.57\%)

Obstructive -01

Mixed -01

Normal - 12

Females (74):Restrictive - 41(56.16\%)

Obstructive $-7(9.45 \%)$

Mixed -2(2.7\%)

Normal - 24(32.87\%)

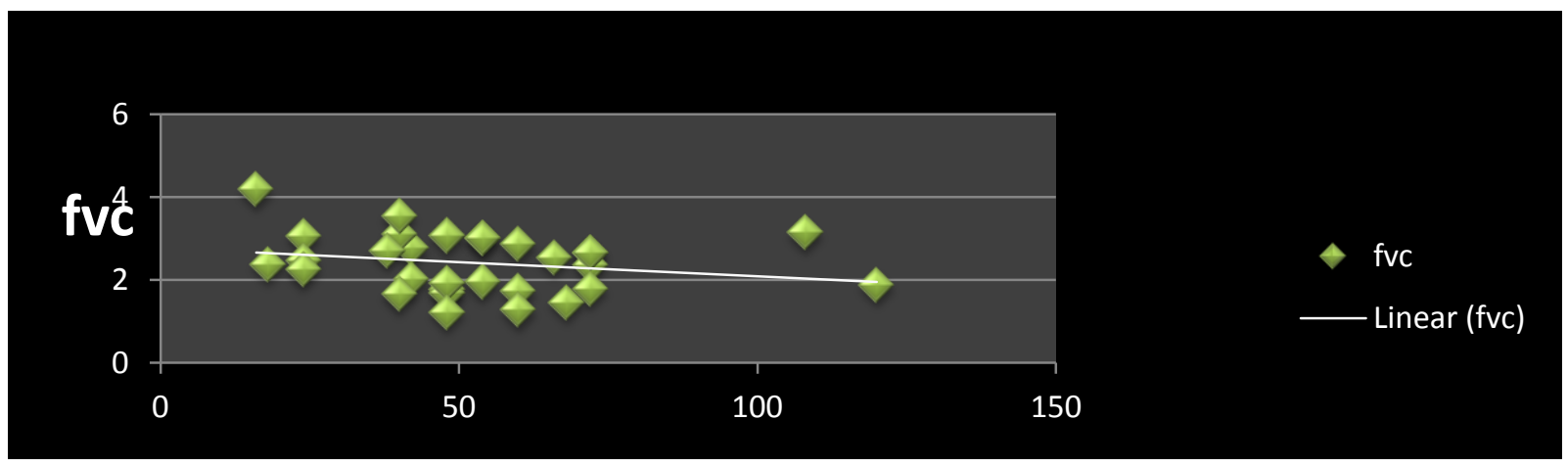

Graph7: Negative Correlation between FVC and duration of diabetes.(smokers) 


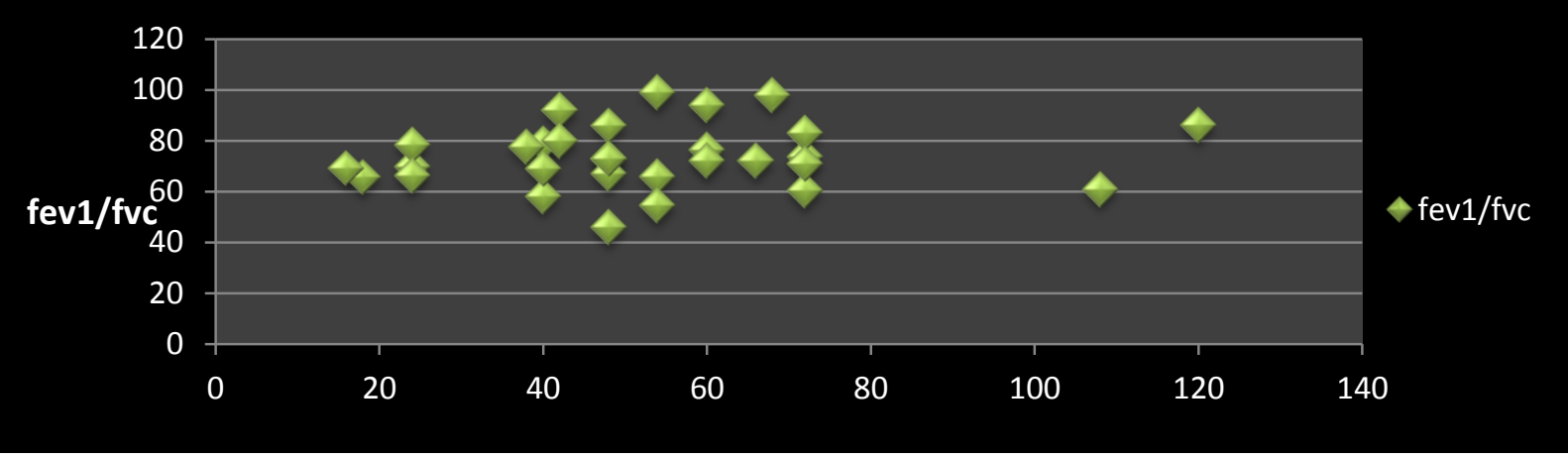

Graph8:Positive correlation between FEV1/FVC and duration of diabetes.(smokers)

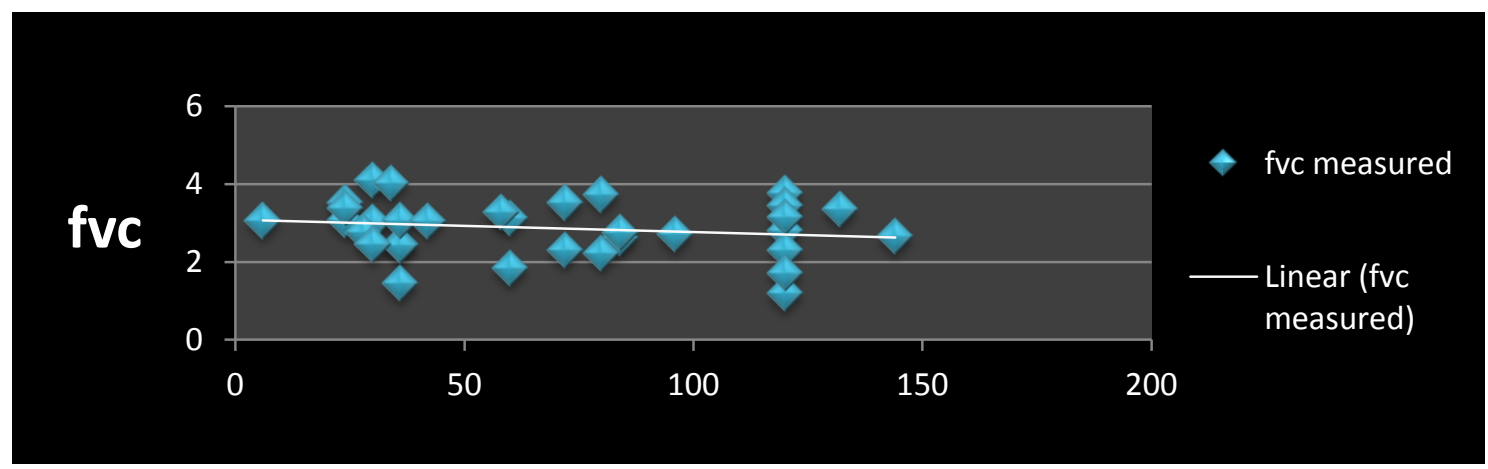

Graph 9: Negative correlation between FVC and duration of diabetes(non smokers)

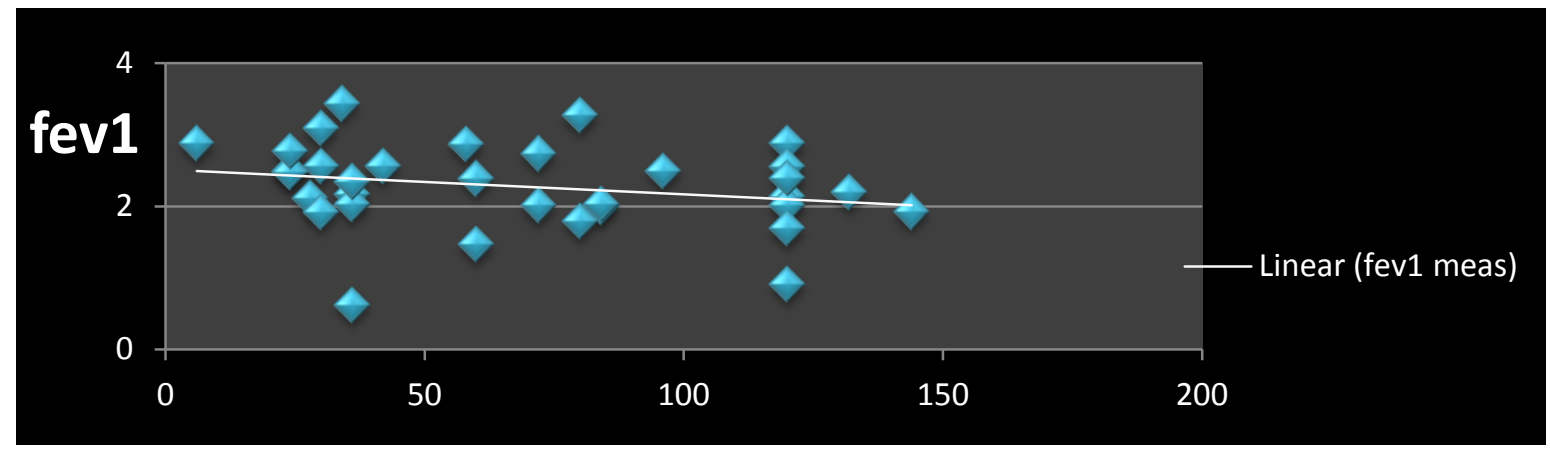

Graph 10:Negative correlation between FEV1and duration of diabetes (non smokers)

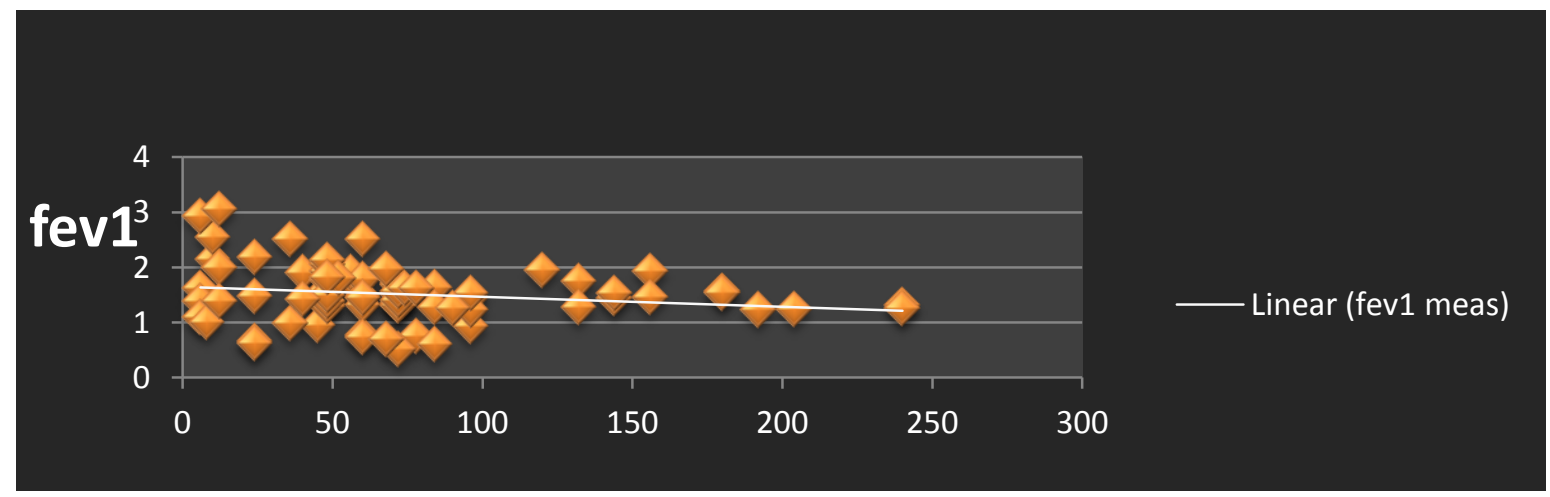

Graph 11: Negative correlation between FEV1 and duration of diabetes (females) 


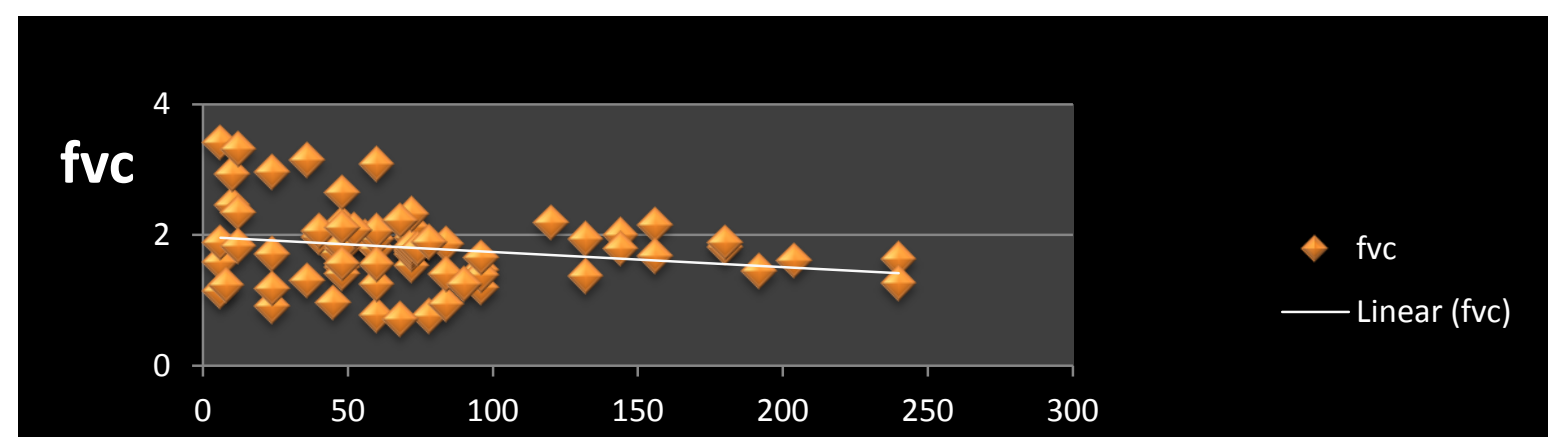

Graph 12: Negative correlation between FVC and duration of diabetes(females)

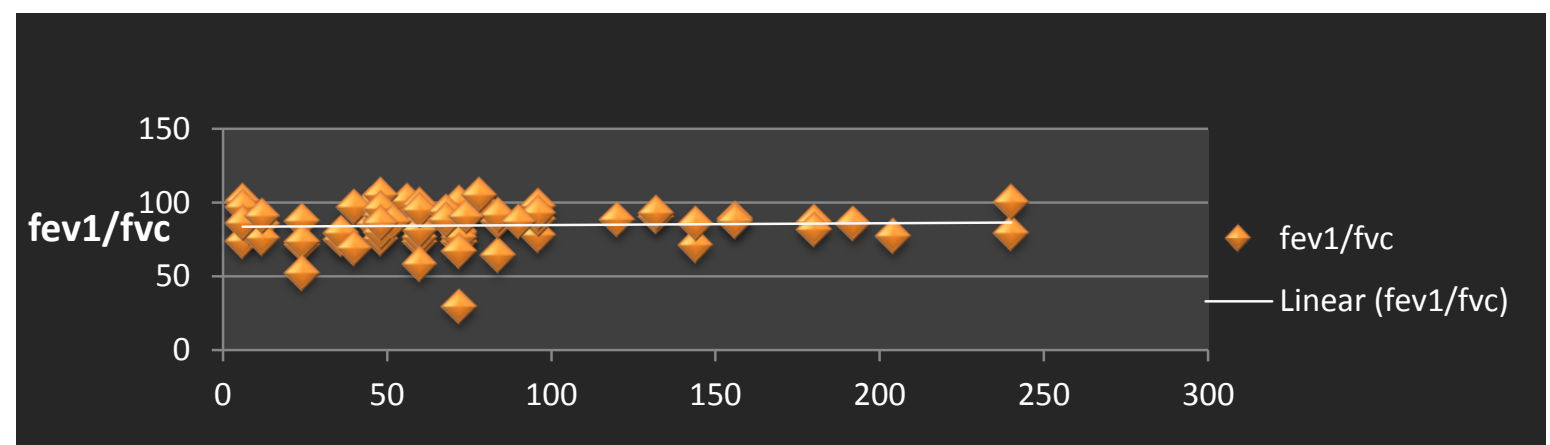

Graph 13: Positive correlation between FEV1/FVC and duration of diabetes (females)

\section{Discussion}

This study was undertaken to assess the ventilatory function of type II diabetic patients and thus to correlate the airflow limitation with the duration of diabetes in these subjects. Similar study was also done by Hiroshi mori etal ${ }^{9}$ where the mean age was the same as in our study and smokers were also included similar to our study. Table XIX

Duration of diabetes was compared with the lung function tests and it was observed that all the parameters i.e. FEV1,FVC, FEV1/FVC were decreased. Poor diabetic control as reflected by HbA1c value was associated with poorer lungunction. These findings were in concordance with study done by P. Lange. ${ }^{10}$

Subjects with smoking history had reduced lung function tests similar to that observed in the study done by Innocenti et $\mathrm{al}^{11}$

Abnormal spiromery was observed in subjects whose mean duration of diabetes was more than 60 months. Rosencker et al ${ }^{12}$ also reported that diabetic patients with duration of 5 years had significant decline in FVC and FEV1 thus again in concordance with our study.

In our study groups, we found predominantly restrictive pattern in non smokers and mixed pattern in smokers whereas in a study done by $\mathrm{S} \mathrm{k}$ Rajan $^{13} 60 \%$ of subjects had an obstructive pattern, 30\% restrictive pattern and the remaining mixed pattern. This difference of findings may be due to inclusion of smokers in our study.

\section{Conclusion}

Abnormal Spirometry was noted in patients who had diabetes of duration more than 48 months. Restrictive pattern was seen in diabetics where as mixed pattern was seen in diabetics who smoke. Poor diabetic control was associated with poorer lung function.

\section{References}

1. Lamande M, Darnaine-Giraud V, Constans T. Diabetes in elderly patients. La Medicine en France. 2006; 54(3):99.

2. King $H$, Aubert RE, Herman WH: Global Burden of Diabetes, 1995-2025 
(Prevalence, numerical estimates, and projections). Diabetes Care 1998; 21: 1414-1431

3. Bela Shah, Narender Kumar, Geetha Menon, Sarabjeet Khurana, Hardeep Kumar. Assessment of Burden of NonCommunicable Disease-Diabetes. A project supported by WHO India office.

4. Movahed, Mohammad-Reza, Hashemzadeh, Mehrtash, Jamal, M Mazen Increased prevalence of Asthma in patients with Type II Diabetes mellitus. Chest 2006; 130: 160S-c

5. Jamal S. Rana, Murray A. Mittleman, Javed Sheikh, Frank B. Hu, JoAnn E. Manson, Graham A. Colditz, Frank E. Speizer, R. Graham Barrand Carlos A. Camargo. Chronic Obstructive Pulmonary Disease, Asthma, and Risk of Type 2 Diabetes in Women. Diabetes Care 2004; 27:2478-2484.

6. Baker, E H, Janaway, C H, Philips, B J, Brennan, A L, Baines, D L, Wood, D M, Jones, $\mathrm{P}$ W. Hyperglycaemia is associated with poor outcomes in patients admitted to hospital with acute exacerbations of chronic obstructive pulmonary disease. Thorax 2006; 61: 284289

7. Robert E. Walter, Alexa Beiser, Rachel J. Givelber, George T. O'Connor and Daniel J. Gottlieb. Association between Glycemic State and Lung Function. The Framingham Heart Study. American Journal of Respiratory and Critical Care Medicine 2003; p167: 911-916.

8. Sunder Mudaliar, and Robert R. Henry. Inhaled Insulin in Patients with Asthma and Chronic Obstructive Pulmonary Disease Diabetes Technol Ther. 2007 June 9; 1:S83-92

9. Mori $\mathrm{H}$ et al Abnormalities in pulmonary function in patients with NIDDM. Internal Medicine 1992; 31; 189-193.
10. P. Lange, S.Groth, J.Kastrup, M. Appleyard, J. Jansen, P. Schnohr Diabetes Mellitus, plasma glucose \& lung function in a cross-sectional population study Eur Resp J 1989, 2.14-19

11. Innocenti F, Fabbri A, Anichini R, Tuci S, Pettina G, Vannucci F, De Giorgio LA, Seghieri G: Indications of reduced pulmonary function in type 1 (insulin-dependent) diabetes mellitus. Diabetes Res Clin Pract 1994; 25:161168.

12. Rosenecker J., Hofler R., Steinkamp G., Eichler I., Smaczny C., Ballmann M., Posselt HG., Bargon J., Von der Hardt H.: Diabetes mellitus in patients with cystic fibrosis: the impact of diabetes mellitus on pulmonary function and clinical outcome. Eur. J. Med. Res. 2001; 6(8): 345-50

13. SK Rajan, P Rajesh Prabhu, Madhu Sasidharan, Spirometric evaluation of type1 DM Abstract of paper presented at APICON 2003, JAPI Vol 50, 1529 December 2002 